(C) 2017. This manuscript version is made available under the CC-BY-NC-ND 4.0 license http:// creativecommons.org/licenses/by-nc-nd/4.0/ 


\title{
Effects of volatile organic compounds on water recovery from produced water via vacuum membrane distillation
}

\author{
Minwei Yao ${ }^{\mathrm{a}}$, Yun Chul Woo ${ }^{\mathrm{a}}$, Leonard D. Tijing ${ }^{\mathrm{a}}$, June-Seok Choi ${ }^{\mathrm{b}}$, Ho Kyong Shon ${ }^{\mathrm{a}, *}$
}

\begin{abstract}
${ }^{a}$ Centre for Technology in Water and Wastewater, School of Civil and Environmental Engineering, University of Technology Sydney (UTS), P. O. Box 123, 15 Broadway, NSW 2007, Australia

${ }^{\mathrm{b}}$ Environment and Plant Research Institute, Korea Institute of Civil Engineering and Building Technology (KICT), 283, Goyangdae-Ro, Ilsanseo-Gu, Goyang-Si, Gyeonggi-Do 411-712, Republic of Korea
\end{abstract}

\begin{abstract}
Membrane distillation (MD) has great potentials to treat produced water in energy industries. However, volatile organic compounds (VOCs) existing in the produced water added in the fracking process can hinder the treatment process regarding two aspects: permeate quality and MD flux performance. To address this challenge, this study aims to systematically study the effects of the VOCs on the MD permeation performance and permeate quality, and the mechanism of its penetration. Acetic acid, ethylene glycol, isopropyl alcohol (IPA), and 2-Butoxyethanol (2-BE), which are commonly found in the produced water, were extensively investigated and their impacts were reviewed and compared. Among all the VOCs, 2-BE had the highest mass transfer despite its low vapour pressure and large molecule weight. Some of the VOCs had surfactant properties, which meant they could penetrate the membrane pores easily during MD process. In long-term operation, pore wetting started to appear as the salt rejection was dropping in the MD process, and flux was also decreasing. Based on the results, this study suggested that the strength of surfactant properties and intra-molecular hydrogen bonds between water molecules and VOCs are as significant as vapour pressure for the VOCs in terms of mass transfer efficiency in MD system.
\end{abstract}

Keywords: Membrane distillation; Gas produced water; Volatile organic compound; Wetting; Surfactant 


\section{Introduction}

Coal seam gas (CSG, coal bed methane) unconventional natural gas resources stored in coal seam layers at a depth of 300-1000 $\mathrm{m}$ while shale gas is usually buried beyond 1,500 $\mathrm{m}$ [1]. Fast replacing coals and conventional natural gas, CSG has been developed into one of most important energy resources for Australian economies (especially for Queensland), which is being greatly exported as liquefied natural gas (LNG) to Asian countries. Similarly, the unconventional gas has become an important energy source in the United States, Canada, and some other countries as well. Although these gas is considered as a relatively "greener" resource as it produced much less carbon dioxide after burning, the processes of gas exploration still pose great risks on the local ecological system. One of the biggest challenges is produced water management $[1,2]$. To mine the gas out of the coal bed, large amounts of water is required to be removed from the coal to reduce the hydrostatic pressure. Formation water, flow back water, and water condensing from the gas phase compose produced water. Formation water is the major contributor to the produced water, naturally occurring and being stored in oil and gas reservoirs. The water is often of brackish to saline quality $[1,3]$.

Management of the produced water is a major challenge in energy industry due to its large amounts, complex chemical compositions, and limited disposal options. In Australia, direct reinjection of the produced water back into the deep underground well is banned, a technique commonly practiced in the United States [4]. Therefore, currently most Australian exploration companies applied reverse osmosis (RO) on site to treat the produced water. The permeate water of RO is sold to local residents for irrigation $[4,5]$. However, RO is not efficient to treat concentrated salty water, so still large amounts of brine could only be stored in the onsite evaporation ponds as short or medium term solution.

Membrane distillation (MD) has strong potentials to further treat the brine or produced water as salt concentration in the feed had minimal effects on its flux performance. Around 95\% recovery of RO brine from the gas produced water had been achieved through the RO-MD hybrid system [6-8]. Regarding salt removal, the quality of the permeate was decent as MD has theoretically $100 \%$ rejection rate for non-volatile solutes [9]. Also, the flux performance is less affected by the salinity of the feed. 
In terms of energy consumption, MD was found to be more efficient than the business-as-usual strategy (BAU) for treatment of the produced water. Tavakkoli found that the operation cost of MD was roughly half of the BAU strategies when low-grade heat was available [10]. However, MD had degraded permeate quality when treating wastewater containing VOCs, dissolved gas, or some small organic particles [11]. Especially, when the VOCs are alcohol or having surfactant properties, membrane wetting will occur and lead to further deterioration of the permeate quality as the feed water can pass through the membrane directly via the wetted pores [11-13]. Recently, some researchers studied the effect of the surfactant and oil existed in the produced water on the water recovery via MD and found that they had strong negative impact on the permeation flux and permeate quality $[12,14]$. However, none of researches have investigated the effect of VOCs in the produced water on the MD performance, which may share similar effects as the surfactant and oil.

It has been found that the compositions of the gas produced water are highly dependent on the geology [15]. In some mining wells, high concentrations of the volatile organic compounds (VOCs), mainly acetic acid, had been found in the produced water [16]; also, the produced water could contain large quantities of VOCs which had been artificially added into the pumping fluids for fracking, especially during initial stage of the mining [15]. A concentration of $1,600 \mathrm{mg} / \mathrm{L}$ acetic acids had been detected in the flow-back water in some wells [17]. The concentration of the VOC in the RO brine can be further increased. Therefore, 2,000 ppm was selected as the baseline concentration for all the VOCs tested in this study to explore their maximum potential impacts. Those VOCs can hinder the MD process regarding permeate quality and water permeation performance [18]. To address this challenge, this study aims to systematically study the effects of commonly found VOCs in the produced water and their mechanism of the membrane penetration. Here, acetic acid, ethylene glycol, isopropyl alcohol (IPA), and 2-Butoxyethanol (2-BE), which are commonly used in the fracking fluids or naturally occurring [15], had been extensively investigated regarding their roles in MD. A fundamental understanding of the effects of VOCs on water recovery from gas produced water via MD can help new membrane and system design, which can further promote the realization of its potential in the application. 


\section{Material and methods}

\subsection{Materials}

Acetic acid was purchased from Chem-supply, Australia. IPA was bought from Merck group, Germany while 2-BE and ethylene glycol were obtained from Sigma-Aldrich, USA. All the VOCs were used as received and their properties are displayed in Table 1. To explore the maximum potential impacts by high concentrations of VOCs in the produced water, 2,000 ppm of the tested VOC was added into deionized (DI) water and the solution was stirred for 15 mins before MD experiment, individually. A second set of experiments using $50 \mathrm{ppm}$ for each VOC was conducted to explore their effects on permeate quality in more general scenarios.

Table 1 Properties of VOCs and concentrations of ion components of the synthetic produced water used in this study

\begin{tabular}{|c|c|c|c|c|c|c|}
\hline Volatile organic & Molecular & Surface & $\log P$ & Boiling & Vapour & Source/ \\
\hline compounds & weight [g & tension & & temperature & pressure at & usage \\
\hline & mol $\left.^{-1}\right]$ & {$\left[\mathrm{mNm}^{-1}\right]$ at } & & {$\left[{ }^{\circ} \mathbf{C}\right]$} & $20^{\circ}[\mathrm{kPa}]$ & \\
\hline
\end{tabular}

\begin{tabular}{|c|c|c|c|c|c|c|}
\hline Acetic acid & 60.1 & 27.3 & -0.17 & 118.1 & 1.6 & Natural occurring \\
\hline $\begin{array}{c}\text { Isopropyl } \\
\text { alcohol }\end{array}$ & 60.1 & 21.4 & 0.05 & 82.6 & 4.1 & $\begin{array}{c}\text { Added as } \\
\text { corrosion } \\
\text { inhibitor in } \\
\text { fracking process }\end{array}$ \\
\hline 2-Butoxyethanol & 118.2 & 26.6 & 0.83 & 171 & 0.1 & $\begin{array}{c}\text { Added as } \\
\text { surfactant and }\end{array}$ \\
\hline
\end{tabular}




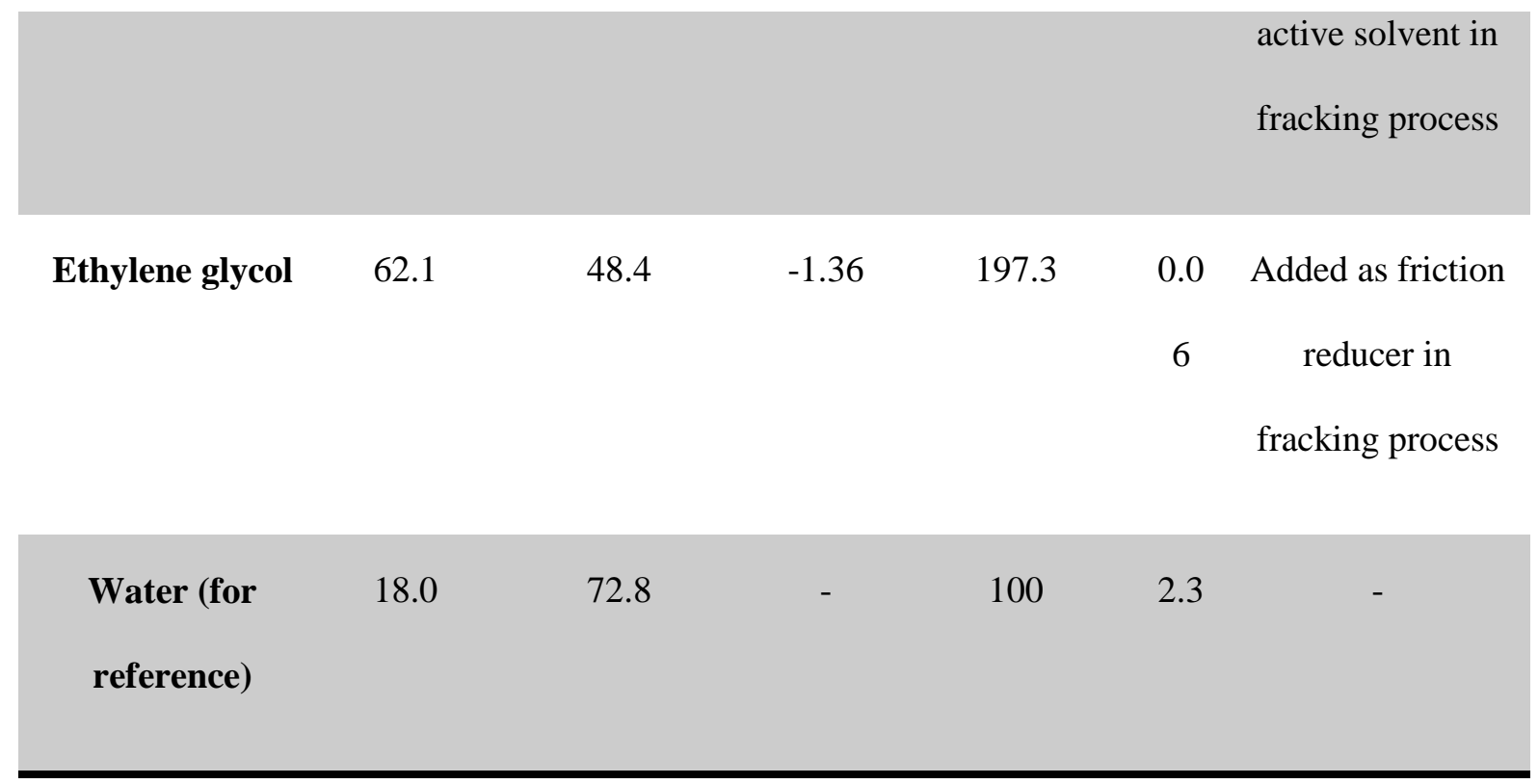

Ion components of RO brine from CSG produced water

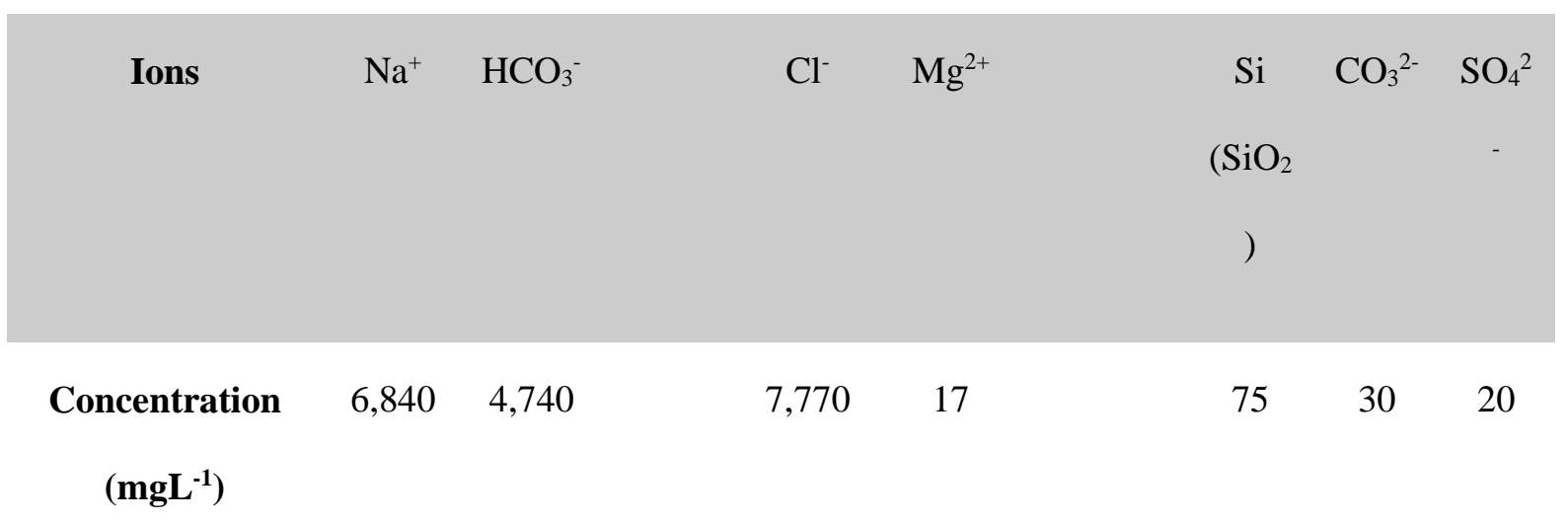

Various chemicals were purchased for the preparation of synthetic CSG RO brine water. Sodium chloride $(\mathrm{NaCl})$ was purchased from Ajax Finechem, Australia. Potassium chloride $(\mathrm{KCl})$ and sodium silicate $\left(\mathrm{Na}_{2} \mathrm{SiO}_{3}\right)$ solution were received from Chem-supply, Australia. Magnesium chloride $\left(\mathrm{MgCl}_{2}\right)$, calcium chloride $\left(\mathrm{CaCl}_{2}\right)$, sodium bicarbonate $\left(\mathrm{NaHCO}_{3}\right)$, sodium carbonate $\left(\mathrm{Na}_{2} \mathrm{CO}_{3}\right)$, and sodium sulphate decahydrate $\left(\mathrm{Na}_{2} \mathrm{SO}_{4} \cdot 10 \mathrm{H}_{2} \mathrm{O}\right)$ were purchased from Sigma Aldrich, USA. All the chemicals were used as received. Composition of the synthetic CSG RO brine is illustrated in Table 1.

\subsection{Vacuum membrane distillation (VMD) configuration}

Vacuum MD (VMD) was used in the study due to its higher thermal efficiency [19]. Polyvinylidene fluoride (PVDF) hollow fiber (HF) membrane was manufactured and provided by Econity, Republic of 
Korea. The HF membranes had inside and outside diameters of $0.77 \mathrm{~mm}$ and $1.3 \mathrm{~mm}$, respectively. Mean pore size, liquid entry pressure, and porosity of the membranes were $0.1 \mu \mathrm{m}, 2.3 \mathrm{bar}$, and $63 \%$, respectively. The HF membranes were used as received without any modification and treatment. Thirteen such HF membranes with length of $0.2 \mathrm{~m}$ were used to make membrane modules for a total surface area of $0.0106 \mathrm{~m}^{2}$, which was placed in the VMD set-up illustrated in Fig. 1. The membrane modules had an internal diameter of $8 \mathrm{~mm}$.

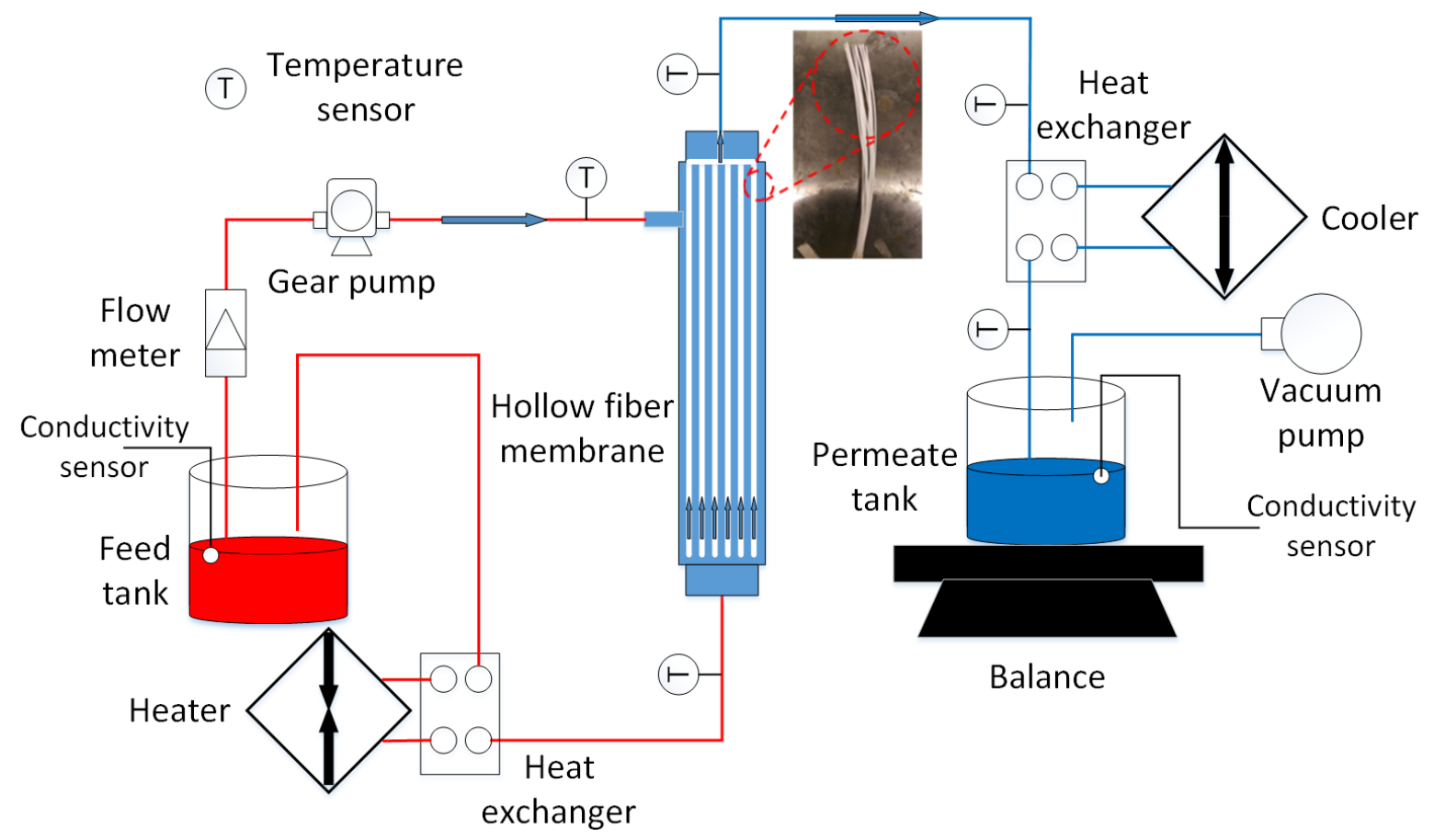

Fig. 1 Schematic diagram of vacuum membrane distillation in this study

We conducted VMD process with various parameters to optimize the system (see Supplementary Information for preliminary results). In the VMD experiments, feed flow rate was maintained at 400 $\mathrm{ml} / \mathrm{min}$ by a gear pump purchased from Cole-Parmer Instrument Company, Australia. Feed temperature was kept at $70^{\circ} \mathrm{C}$ by a heat exchanger (DSB 193-11 F) provided by Daesung Engineering, Republic of Korea. Another heat exchanger of same model set at $15^{\circ} \mathrm{C}$ was used to condense the water vapour. Vacuum pressure was set at 850 mbar by a vacuum pump (PC 3001 Vario pro) from John Morris Scientific, Australia. Same setup was used in long-term operation test. For each experiment, a new 
membrane module was made, and before the start of each experiment, they were tested using DI water as feed for $3 \mathrm{~h}$ to make sure that they had identical flux performance. The permeate flux, J, was calculated as per Eq. (1):

$J\left(L m^{-2} h^{-1}\right)=\frac{\Delta M}{\rho * A * t}$

, where $\mathrm{J}$ is the permeate flux $\left[\mathrm{Lm}^{-2} \mathrm{~h}^{-1}\right], \Delta \mathrm{M}$ is the mass of collected permeate $[\mathrm{kg}], \rho$ is the density of permeate water (assumed to be $1 \mathrm{~kg} / \mathrm{L})$, A is the total surface area of the membrane $\left(0.0106 \mathrm{~m}^{2}\right.$ in this study), and $t$ is operation duration [h]. The salt rejection, $R$, is given in Eq. (2):

$R(\%)=1-\frac{C_{p}}{C_{f}}$

, where $C_{p}$ and $C_{f}$ are the concentration of the permeate and feed $\left[g \cdot L^{-1}\right]$, respectively. The concentrations of inorganic salts in the feed and permeate solutions were measured with electrical conductivity meters (HQ40d, Hach).

\subsection{Characterizations}

Total organic carbon (TOC) was measured using a high-performance TOC analyzer (multi N/C3100®) which was purchased from Analytikjena, Germany. Attenuated total reflection-fourier transform infrared spectroscopy (ATR-FTIR) (IRAffinity-1 with MIRacle 10) was purchased from Shimadzu, Japan, which had penetration depths from 1.2 to $2.4 \mu \mathrm{m}$ for detection spectrum from 2000 to $4000 \mathrm{~cm}^{-}$

1. It was used to investigate the mechanism of VOC movements through the HF membranes by measuring the shell and lumen sides of the used membranes. Each spectrum was obtained with signal averaging 32 scans at a resolution of $4 \mathrm{~cm}^{-1}$ in transfer mode by pressing the sample with $\mathrm{KBr}$ to a pellet [13]. Contact angles of the virgin and used HF membranes were measured by Theta Lite 100 (Attension) using a sessile drop method [20,21]. A water droplet around $5 \mu 1$ was released from a needle tip onto the flatted HF membrane surface. A motion camera was mounted to capture the videos at a rate of 12 frames per second. Using the Theta Lite software, contact angles were analyzed automatically. Each set of HF membrane samples were measured for three times and the average value of them was taken. 


\section{Results and discussions}

\subsection{Effects of VOCs on MD performance}

\subsubsection{VMD treatment of synthetic brine water}

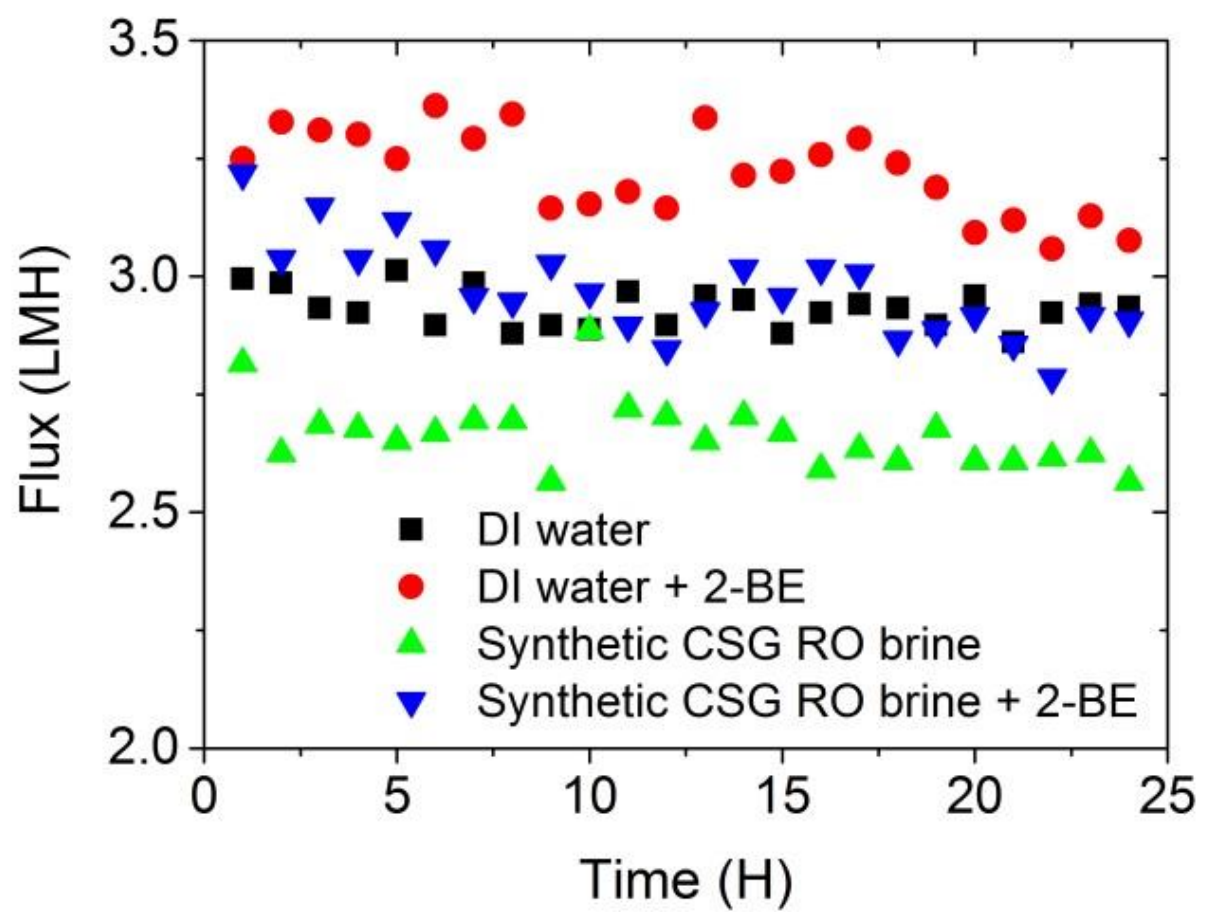

Fig. 2 Effects of 2-butoxyethanol on flux when treating de-ionized water and synthetic produced water

To determine the effects of the VOCs on the VMD flux performance, 2-BE was first selected as a representative VOC to be added into the synthetic produced water for comparison because it was widely applied in the industries and has attracted lots of academic interests for its effect on the local ecological systems $[2,15,16]$. The features of the VMD setup caused some relatively big errors of the flux in various hours (Fig. 2). Due to the adhesion between liquid water and tube lines, the condensed vapour sometimes is temporarily stuck in the pipelines, waiting to be discharged into the permeate tank altogether when more of it has been accumulated. Nevertheless, we can still confidently observe the trend of flux showing that the addition of 2-BE into the synthetic water increases the average flux of VMD from 2.9 to $3.3 \mathrm{LMH}$ in $24 \mathrm{~h}$ operation, which was due to the mass transport of 2-BE. Also, a 
decline in flux when treating produced water containing 2-BE was observed, which could be caused by the partial pore wetting [18]. Its mechanism will be discussed in the later sections. Addition of 2-BE into the synthetic produced water contributed to the increase in the overall permeation flux and its gradual declining trend, which was consistent with the result when 2-BE was added into the DI water as feed. The declining trend of flux was not observed when treating feed without 2-BE regardless of using DI or synthetic produced water as feed.

Concentrations of the feed and the permeate were measured before and after the VMD process, and it was found that a salt rejection of $99.99 \%$ was achieved regardless of the presence of 2-BE in the feed. Meanwhile, after treating synthetic produced water with 2-BE via VMD, a very high concentration of 2-BE could be found in the permeate, reaching 3,260 ppm, which was much higher than the initial concentration of 2,000 ppm in the feed. The high mobility of 2-BE was reported in previous study concerning the impact of the fracking process on local ecological system, where it was used as a surfactant and active solvent [16]. However, it was still unexpected that 2-BE severely penetrated the membrane in VMD process considering that it had much lower vapour pressure than water (0.1 vs. 2.3 $\mathrm{kPa}$ at $20^{\circ} \mathrm{C}$ ). Hence it is essential to study whether other common VOCs existing in the produced water posed similar challenges, and what characteristics of the VOCs, except vapour pressure, affect their mass transfer in the MD systems, along with their penetration mechanism.

\subsubsection{Comparison of flux using various VOCs as feed}




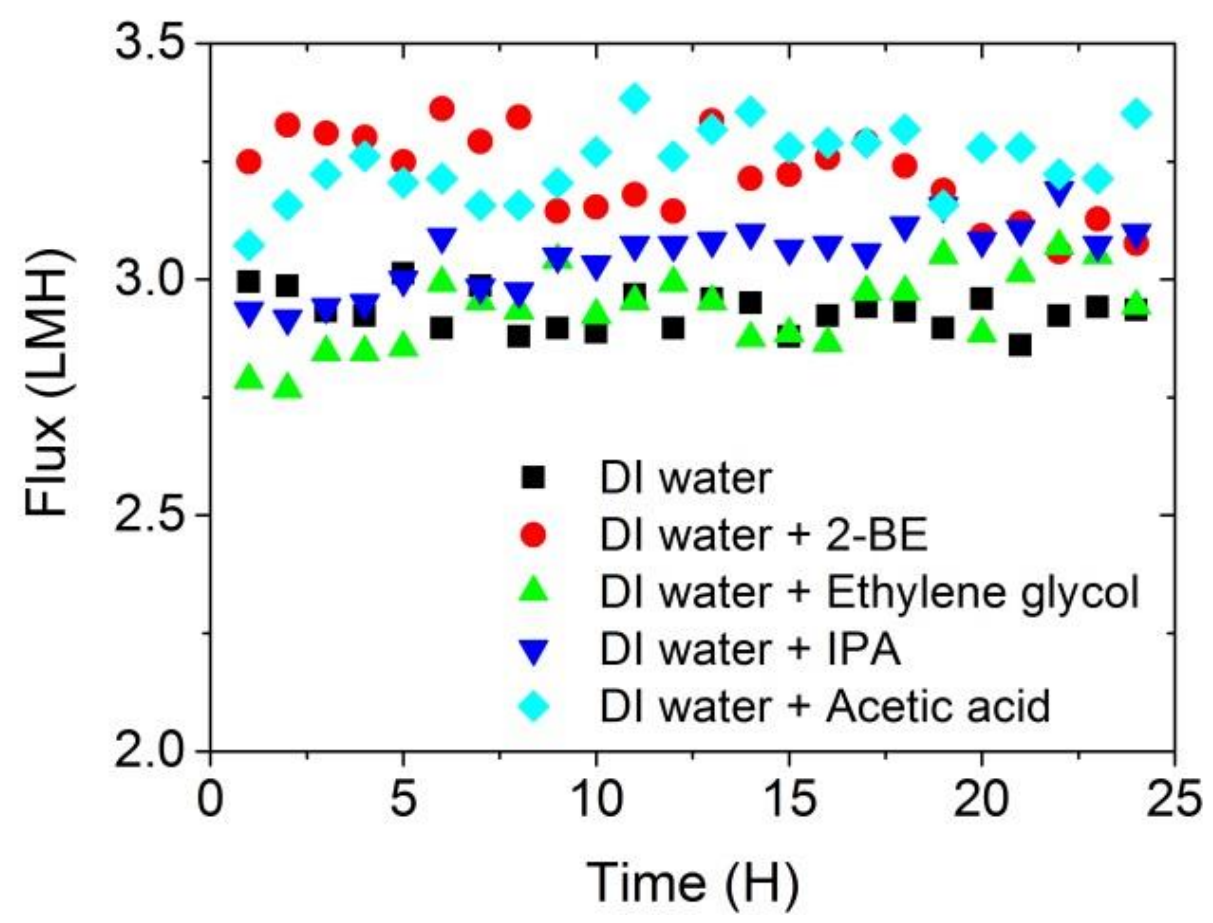

Fig.3 Effects of various volatile organic compounds on flux when treating de-ionized water

Various popular VOCs used in fracking process namely acetic acid, 2-BE, ethylene glycol and IPA, had been investigated regarding their effects on the VMD flux performance. Fig. 3 shows that the addition of VOCs in the DI water, except ethylene glycol, led to an obvious increase in the average flux. The increase of the flux after the injection of IPA into the feed can be explained by the increase of partial pressures [22]. Similarly, addition of ethylene glycol into feed led to the lowest VMD performance because of its extremely low vapour pressure [23]. However, among all the tested VOCs, feed with acetic acid had the highest average flux although acetic acid had much lower vapour pressure than IPA; its vapour pressure is even lower than water. Also, 2-BE, which had the second lowest vapour pressure among all, shows impressive mobility in this study. It has the highest initial flux and the second highest average flux for $24 \mathrm{~h}$ operation. IPA was expected to result in the highest flux increase as it had highest vapour pressure; however, it was outperformed by acetic acid and 2-BE, both having even lower vapour pressures than water. Therefore, the high flux of VMD treating feed water containing acetic acid and 2BE indicated that there were some characteristics of VOC, other than boiling temperature, surface tension, and vapour pressure, contributing to their high mobility in VMD. Some researchers discussed 
about the mechanism of "adsorption-desorption" for some organic chemicals with hydroxyl and carboxylic group [24, 25] when trying to explain the movement of certain types of organic compounds from feed to permeate side without membrane wetting occurring. This mechanism could explain the high mobility of 2-BE and acetic acid. It is also worth noting that only the addition of 2-BE into DI water caused obvious decline in the VMD flux.

Another series of VMD experiments with same concentrations of VOCs had been conducted, only replacing DI water with $1.0 \% \mathrm{NaCl}$ as feed base. Nearly identical flux and VOCs mass transfer could be found after $24 \mathrm{~h}$ operation, and salt rejection of the VMD experiments was found to be $99.99 \%$, indicating that the membrane pores were not wetted during the processes (Table S1).

\subsubsection{Mass transfer of VOC from feed to permeate}
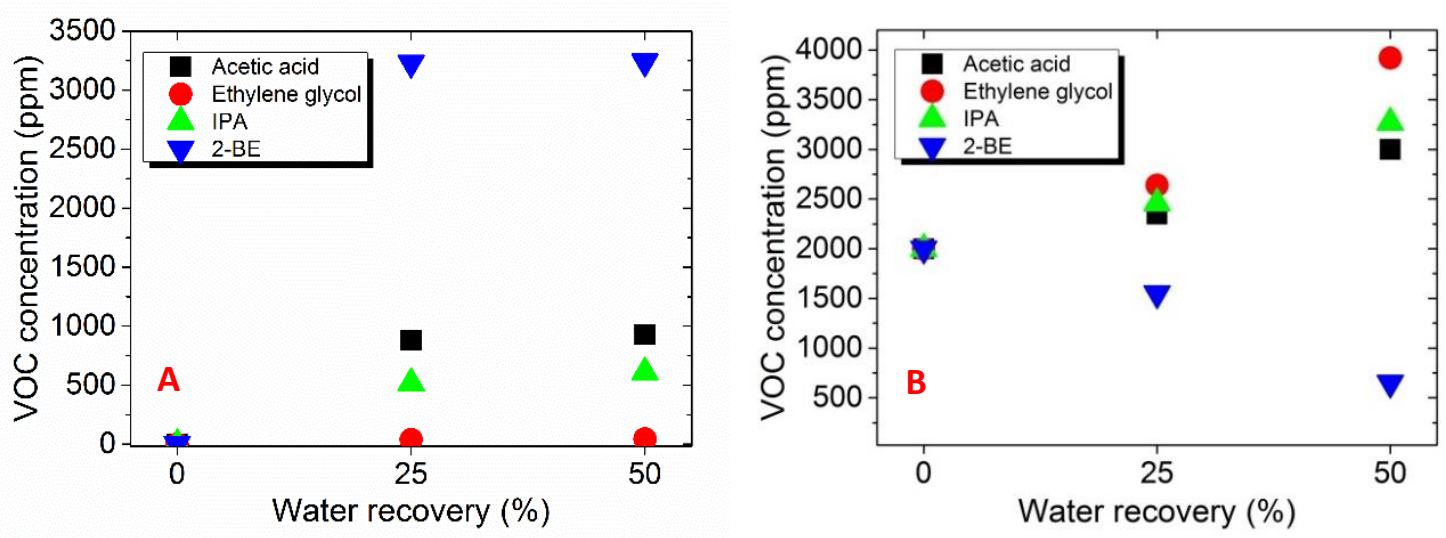

Fig. 4 Changes in concentrations of various volatile organic compounds in A) permeate; and B) feed sides (initial feed VOCs concentrations: 2,000 ppm)

To confirm the mass transport of VOCs which led to increase in flux for feed containing VOCs, measurement of feed and permeate concentration of VOCs had been carried out individually at various water recovery rates. Fig. 4A shows that concentrations of various VOCs (except ethylene glycol) in permeate solution increased when the water recovery increased, while only the concentrations of 2-BE decreased in the feed solution (Fig. 4B). Owing to its higher boiling point, surface tension, and lowest $\log \mathrm{P}$, there was no mass transfer of ethylene glycol through the membrane during MD process as its concentration in the permeate was maintained ignorable while the one in the feed doubled. IPA and 
acetic acid shared similar mass transfer rate. Concentration of acetic acid was slightly higher in permeate than IPA although acetic acid had much lower vapour pressure. 2-BE had very different trends of concentration from the other VOCs. 2-BE concentrations in feed decreased rapidly during the VMD process (Fig. 4B). When water recovery reached 50\%, the 2-BE concentrations in permeate (3,240 ppm) exceeded the initial feed concentration (2,000 ppm), which meant that the mobility of 2-BE was much higher than water in the MD process even though it had higher boiling temperature and lower vapour pressure. The "adsorption-desorption" mechanism might play an important role in the phenomenon, which involved the strong hydrogen bond between the 2-BE and water molecules. The mechanism of the VOCs' behavior would be further discussed in the later sections of this paper.

To determine the permeate quality of MD-treated produced water, a more general concentration of VOC in the produced water were introduced. $50 \mathrm{ppm}$ concentration of each VOC had been added into the feed for comparison of the change of the concentrations in both feed and permeate solution. A similar pattern of the changes could be observed in Fig. 5. Compared with the patterns using high concentration of VOCs, a decrease in the mass transfer rate of VOCs could be observed, which might be caused by a decreased partial pressure. However, the concentration of acetic acid, IPA, and 2-BE in the permeate is still too high to be used as drinking water. A post-treatment is then required the reduce the TOC of the permeate water.
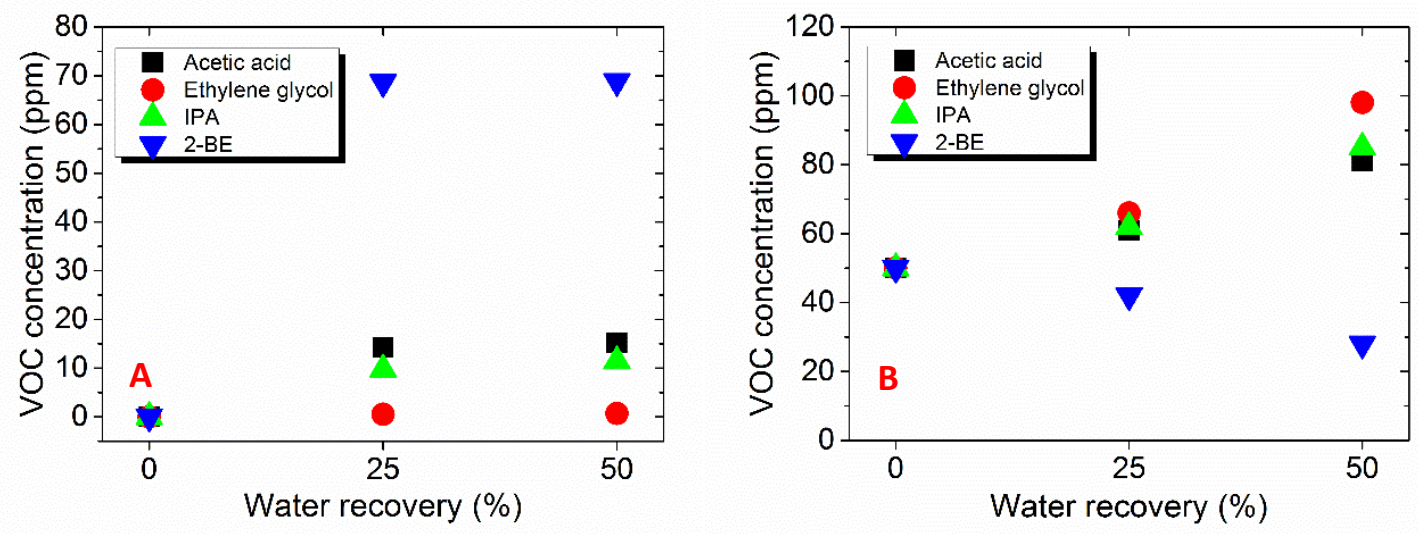

Fig. 5 Changes in concentrations of various volatile organic compounds in A) permeate; and B) feed sides (initial feed VOCs concentrations: 50 ppm) 


\subsection{Effect of VOCs on the membranes}

\subsubsection{Penetration of VOCs and water into the membranes}

Fig. 6A shows the ATR-FTIR measurement of the shell and lumen sides of membrane samples that have treated VOCs feeds via VMD for $24 \mathrm{~h}$. Ethylene glycol was not tested in this experiment set because of their low vapour pressure and failure to penetrate the membranes. The penetration depth of the FTIR ranged from 1.2 to $2.4 \mu \mathrm{m}$ for detection spectrum from 2000 to $4000 \mathrm{~cm}^{-1}$. Membranes that have treated DI water display the smallest peak of absorption in the range of 3500 to $3700 \mathrm{~cm}^{-1}$ [25], indicating free hydroxyl $(\mathrm{OH})$ bonds stretching at very low concentration. The free $\mathrm{OH}$ bonds represented the trapped water vapour or VOC traces in the HF membrane pores. When analyzing HF membranes that had treated feed water containing acetic acid, IPA or 2-BE, much larger peaks could be observed in the range of 3500 to $3700 \mathrm{~cm}^{-1}[12,27]$. It was contributed by the VOC traces trapped in the membrane pore. The deeper peaks indicate more VOC molecules trapped in the membrane pores on the shell side. Moreover, Fig 6A displays that when 2-BE was added into the feed, a large broad peak in the range of $3200-3600 \mathrm{~cm}^{-1}$ appeared, which were $\mathrm{H}$-bounded $\mathrm{OH}$ in stretching mode. It represented the liquid water [12,27]. Because of strong surfactant properties of 2-BE, the surface tension of the feed solution decreased remarkably, leading to partial pore wetting on the membrane shell side. $[26,28]$. It explained that the feed containing 2-BE had decreasing flux performance in VMD although the salt rejection was maintained high. Fig. 6B shows the FTIR analysis of the lumen side of the operated HF membranes, indicating that higher amounts of acetic acid and 2-BE than IPA were trapped in the membrane pores at lumen side, while all three samples that treated the VOCs show deeper peak in the range of 3500 to $3700 \mathrm{~cm}^{-1}$ than the one had treated DI water. Broad peaks in the range of 3200$3600 \mathrm{~cm}^{-1}$ did not appear in the lumen side of the HF sample that had treated feed containing 2-BE, indicating that the liquid water had not reached the lumen side of the membrane after $24 \mathrm{~h}$ operation yet [12]. 

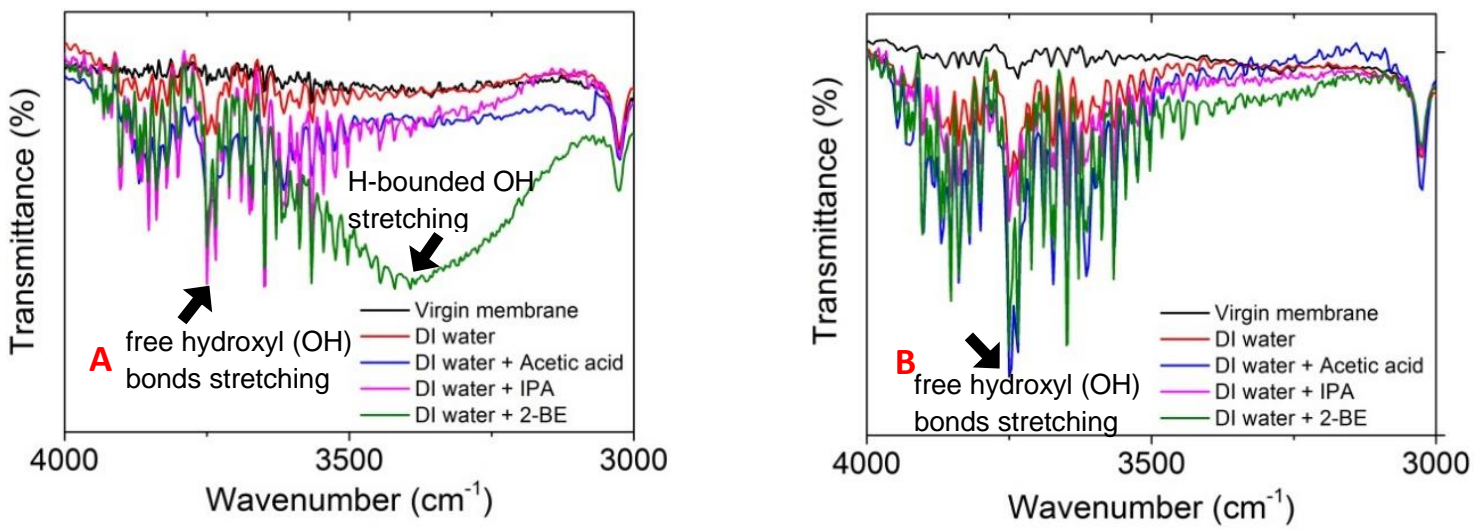

Fig. 6 FTIR analysis of membranes after $24 \mathrm{~h}$ operation: (A) shell side (feed) (B) lumen side (permeate)

The fast wetting of membranes did not occur when VOCs were added into the feed (Fig. 6 and Table S2) because a very high concentration ( $>5 \mathrm{wt} \%$ ) of them (except 2-BE) are required to significantly reduce the surface tension of water mixtures and hence LEP of the membrane [29]. 2-BE, as a nonionic surfactant, is able to reduce the surface tension of the mixtures more effectively. However, the strength of its surfactant properties is much weaker than the common long-chain surfactants (e.g. Tween 20). The critical mole fraction of 2-BE is around 0.0131 at $55^{\circ} \mathrm{C}[30]$, which is much higher than the used mole friction in this study. Also, the fast mass transfer of the 2-BE on the membrane surface further decreased its effects on the reduction of LEP although partial wetting started to occur during the VMD process. Considering the relatively low concentration of VOCs used in this study, we can confidently address that the added VOCs had limited effects on the surface tension and hence liquid entry pressure.

\subsubsection{Contact angle}

Contact angle was measured to investigate the effect of the VOCs on the HF membrane. Fig. 7 shows that after treating DI water, or ethylene glycol, the contact angle of the HF membranes hardly changed. After treating acetic acid and IPA, the contact angle of the membranes decreased slightly due to their weak surfactant properties, as some traces of the VOCs started to adhere on the membrane surface. On 
the other hand, treating feed with 2-BE could result in significant decrease in contact angle of the HF membranes $(10 \%)$ owing to its relatively strong surfactant properties and partial pore wetting on the membrane surface [15].

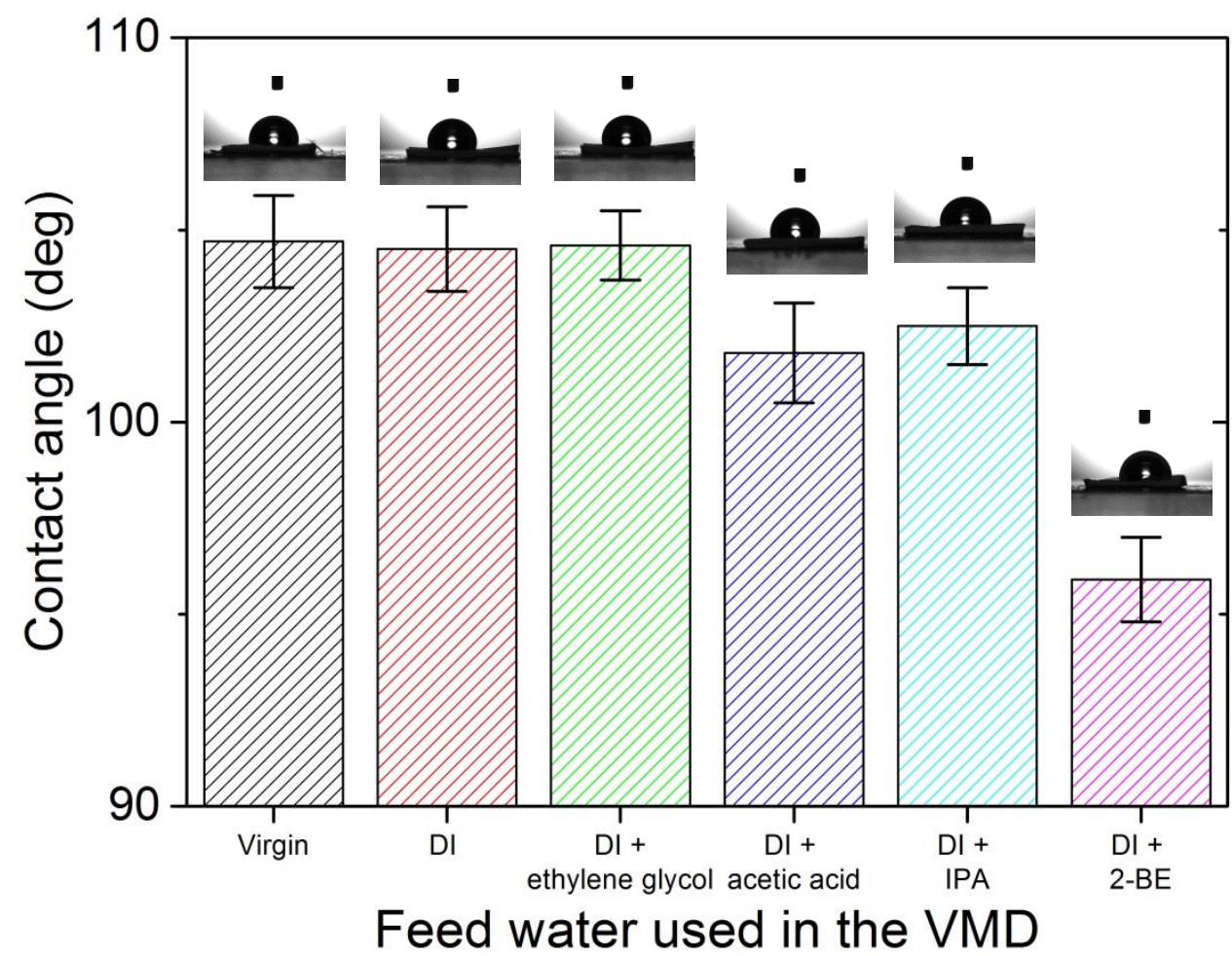

Fig. 7 Contact angle of membranes after treating various VOCs for $24 \mathrm{~h}$ in VMD

\subsection{Long-term operation performance with feed containing 2-BE}

\subsubsection{Flux}

Surfactants in the feed water were found to cause membrane wetting rapidly $[12,14]$. When treating the feed that contained 2-BE for $24 \mathrm{~h}$, partial pore wetting appeared as the flux started to decline (Fig. 2). Therefore, a complete pore wetting was expected in long-term operation. The same VMD setup was implemented for the long-term operation study. The setup was kept running for $72 \mathrm{~h}$ to treat $2 \mathrm{~L}$ synthetic produced water containing 2,000 ppm of 2-BE. Every $24 \mathrm{~h}$ the permeate container vessel was emptied and new $2 \mathrm{~L}$ synthetic produced water with 2,000 ppm 2-BE was filled into the feed container 
(water recovery $<60 \%$ ), and we recorded the flux only when the feed temperature became stabilized at $70^{\circ}$ after replacing the feed. Fig. 8 shows that the flux had a gradual decreasing trend during $72 \mathrm{~h}$ VMD operation. It was caused by the decrease in 2-BE concentration in the feed and partial pore wetting of the HF membranes as the existence of the salts had minimal effect on the decrease in the flux (Fig. 2). It was worth noting that after the feed concentration was increased back to $2,000 \mathrm{ppm}$ after $24 \mathrm{~h}$ operation, the flux recovered to some extent although it was still lower than the initial flux. This proved that the decrease in flux over time was caused by the decrease of 2-BE concentration in the feed. After $72 \mathrm{~h}$ operation, salt rejection of VMD dropped to $99.97 \%$, which meant that complete pore wetting started to appear as average flux was decreasing comparing three periods of $24 \mathrm{~h}$ operation [12, 31]. Further measurement was carried out to confirm the status of the pore wetting, which was illustrated in next section. A previous report recorded decreased flux when complete pore wetting occurred while some others observed increased flux [32]. The use of membranes with smaller mean pore sizes is assumed to cause the decreased flux when wetting occurring. In this study, a membrane with a small pore size is used $(0.1 \mu \mathrm{m})$, which leads to a much higher resistance between the liquid water and membrane matrix. So when wetting occurs, these liquid will block the pathway of the vapour, decreasing the total water flux. In a recent study, the authors used a membrane with average pore size below $0.2 \mu \mathrm{m}$ in MD, and they found the flux started to decline when wetting induced [32]. 


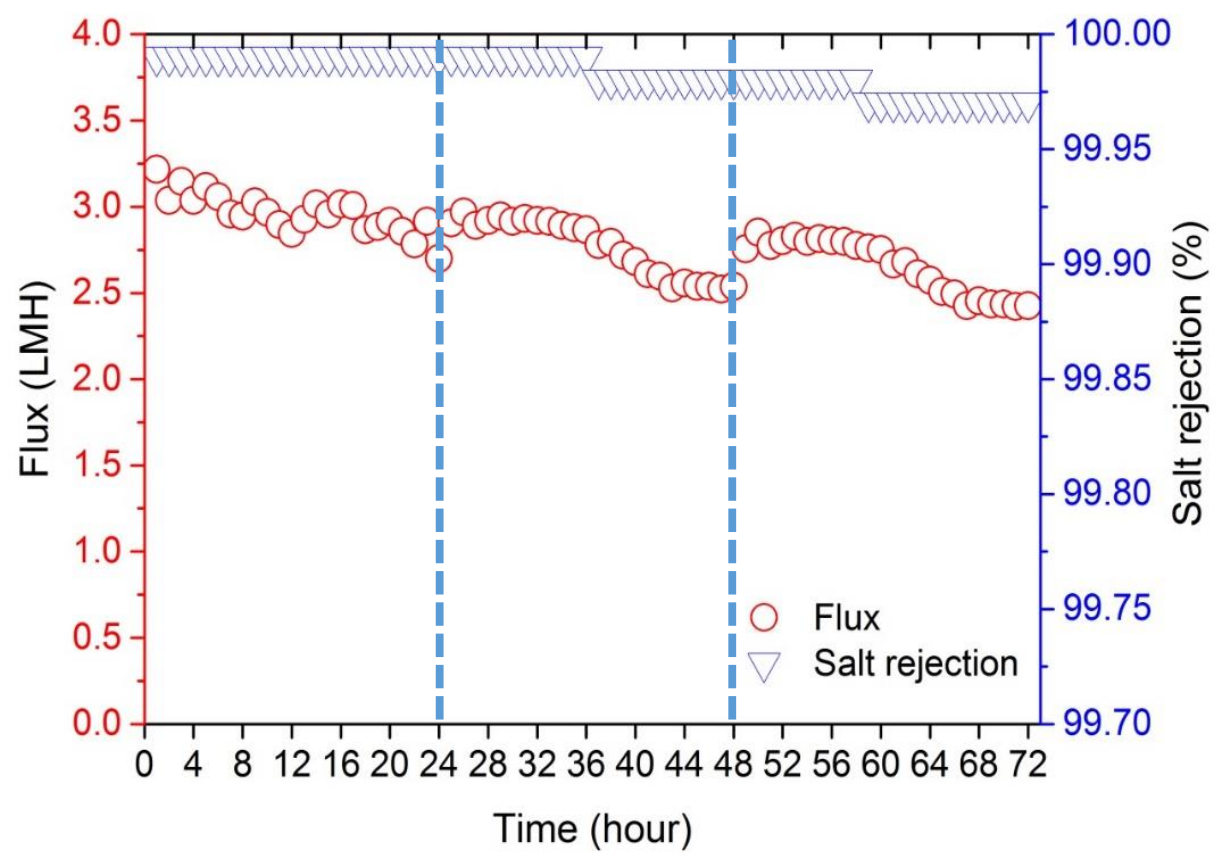

Fig. 8 Flux of VMD treating synthetic CSG RO brine containing 2-BE for $72 \mathrm{~h}$

\subsubsection{Penetration of 2-BE and water through the membrane}

FTIR measurement was conducted on both shell and lumen sides of the HF membranes that had treated the feed containing 2-BE for $72 \mathrm{~h}$. Compared with membrane that treated the same feed for $24 \mathrm{~h}$, a deeper broad peak in the range of 3200-3600 $\mathrm{cm}^{-1}$ could be observed on the membrane shell side, which meant that more severe pore wetting occurred as more liquid water had penetrated the membrane surface and remained inside of the pores (Fig. 9A) [12, 33]. Moreover, an analysis on the lumen side shows that the liquid water has further travelled and reached the inner layers of the HF membranes (Fig. 9B). This indicated that complete pore wetting started to occur as salt rejection was dropping as well. 

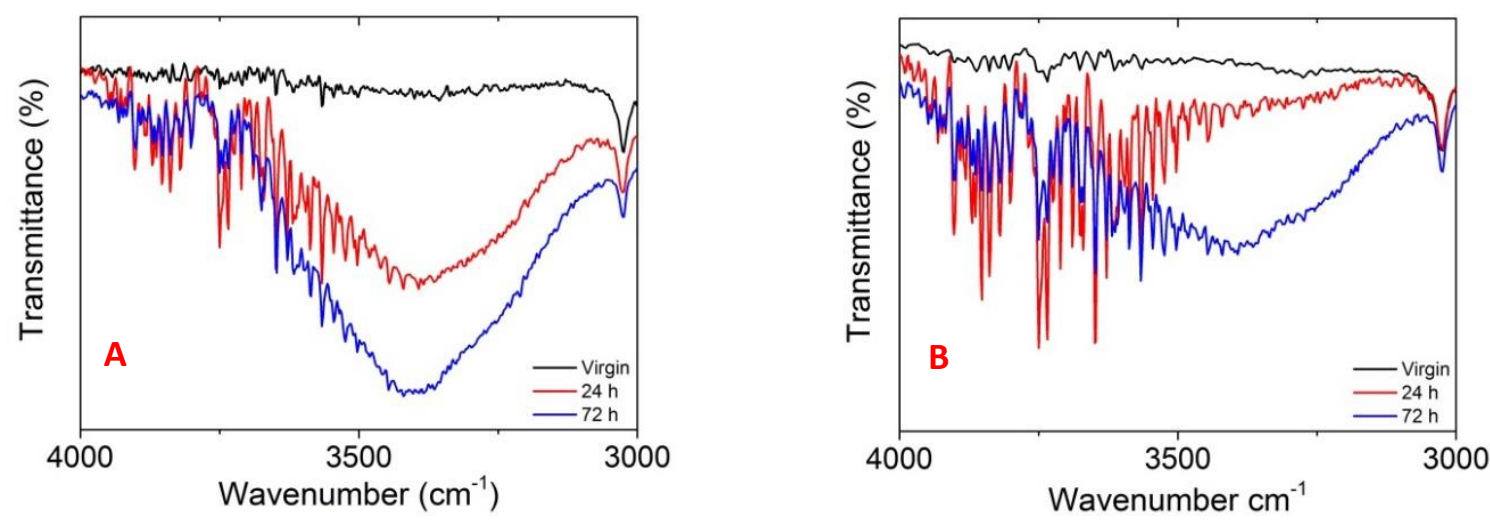

Fig. 9 FTIR analysis of both a) shell and b) lumen sides of membranes after $24 \mathrm{~h}$ and $72 \mathrm{~h}$ operations using feed with and without 2-BE addition.

\subsubsection{Contact angle}

A contact angle measurement was conducted on the HF membranes after $72 \mathrm{~h}$ VMD operation. The existence of minerals in the synthetic produced water had insignificant effect on the contact angle as a marginal decrease from $104.7^{\circ}$ to $104.1^{\circ}$ was noticed after $24 \mathrm{~h}$ operation (Fig. 10). On the other side, addition of 2-BE into the synthetic CSG RO brine caused the contact angle of membranes reduced from $104.7^{\circ}$ to $95.9^{\circ}$ after $24 \mathrm{~h} \mathrm{VMD} \mathrm{operation,} \mathrm{and} \mathrm{it} \mathrm{further} \mathrm{dropped} \mathrm{to} 78.1^{\circ}$ after $72 \mathrm{~h}$ operation. The decrease in contact angle was caused by both the surfactant properties of 2-BE which adhered on the membrane surface, and pore wetting caused by the 2-BE. 


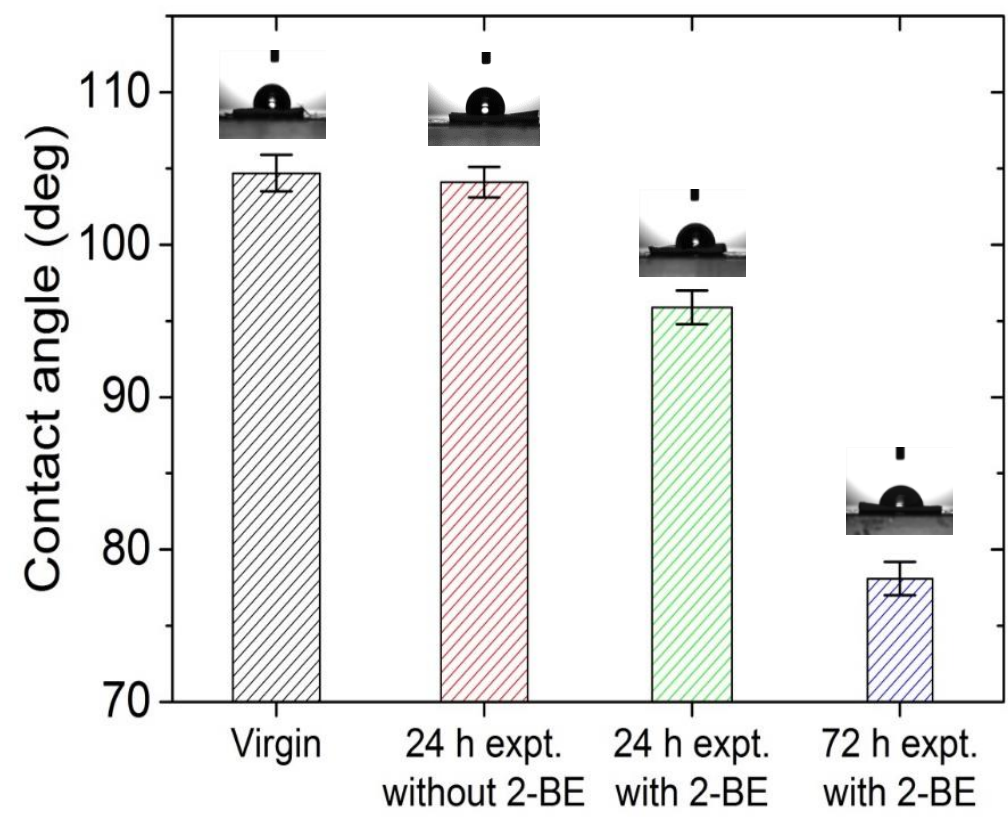

Fig. 10 Contact angle of HF membranes after treating synthetic produced water containing 2BE after 24 and $72 \mathrm{~h}$ operation via VMD

\subsubsection{Comparison of effects with long-chain surfactants regarding their wetting behaviours}

Table 2 shows that the effects of 2-BE as a surfactant on MD performance regarding wetting is very different from the effects of common long-chain surfactant in the literature. The complete pore wetting occurred in a much slower pace even when the 2-BE had a larger concentration than the others. Hydrophile-lipophile balance (HLB) is considered as one of main factor affecting membrane wetting rate $[12,31]$. Generally, the lower HLB leads to a faster wetting rate. However, 2-BE, a volatile organic compound, had a low wetting rate with a relatively low HLB value of 16 . The unique phenomenon is assumed to be as a result of its rapid transport through the membrane to the permeate side as fast increase in the concentration of 2-BE in the permeate side was observed. The mechanism of surfactants causing wettings through its interaction on the membrane surfaces has been extensively studied. However, a much slower wetting process and faster mass transfer through the membrane were noticed when 2-BE was added into the feed, which requires further investigations. It is noted that 2-BE is both a volatile 
organic compound and a surfactant, with the ability of forming strong hydrogen bonds with water molecules. The mechanism of its mass transfer is presented in next section, detailing its transfer process.

Table 2. Comparison of effects with long-chain surfactants regarding membrane wetting behaviours in the literature

\begin{tabular}{|c|c|c|c|c|c|c|}
\hline $\begin{array}{l}\text { MD } \\
\text { configuration }\end{array}$ & $\begin{array}{l}\text { Membrane } \\
\text { types }\end{array}$ & $\begin{array}{l}\text { Feed } \\
\text { solution }\end{array}$ & Surfactant & $\begin{array}{l}\text { Hydrophile- } \\
\text { lipophile } \\
\text { balance }\end{array}$ & $\begin{array}{l}\text { Wetting } \\
\text { phenomenon }\end{array}$ & Reference \\
\hline DCMD & $\begin{array}{l}\text { Commercial } \\
\text { PVDF }\end{array}$ & $\begin{array}{l}\text { CSG RO } \\
\text { brine }\end{array}$ & $\begin{array}{l}\text { Up to } 0.7 \\
\mathrm{mM} \text { of SDS }\end{array}$ & 40 & $\begin{array}{l}98.8 \% \text { salt } \\
\text { rejection } \\
\text { after } 10 \mathrm{~h} \\
\text { operation }\end{array}$ & [8] \\
\hline DCMD & $\begin{array}{l}\text { Commercial } \\
\text { PTFE }\end{array}$ & $\begin{array}{l}700 \mathrm{mg} / \mathrm{L} \\
\mathrm{NaCl}\end{array}$ & $\begin{array}{l}10 \mathrm{mg} / \mathrm{L} \\
\text { Tween } 80\end{array}$ & 11 & $\begin{array}{l}76.2 \% \text { salt } \\
\text { rejection } \\
\text { after } 4 \mathrm{~h} \\
\text { operation }\end{array}$ & [33] \\
\hline DCMD & $\begin{array}{l}\text { Commercial } \\
\text { PTFE }\end{array}$ & $\begin{array}{l}700 \mathrm{mg} / \mathrm{L} \\
\mathrm{NaCl}\end{array}$ & $\begin{array}{l}10 \mathrm{mg} / \mathrm{L} \\
\text { Tween } 20\end{array}$ & 16.7 & $\begin{array}{l}80.6 \% \text { salt } \\
\text { rejection } \\
\text { after } 4 \mathrm{~h} \\
\text { operation }\end{array}$ & [33] \\
\hline DCMD & $\begin{array}{l}\text { Commercial } \\
\text { PVDF }\end{array}$ & $\begin{array}{l}35,000 \\
\mathrm{mg} / \mathrm{L} \mathrm{NaCl}\end{array}$ & $\begin{array}{l}50 \mathrm{mg} / \mathrm{L} \\
\text { Span } 20\end{array}$ & 8.6 & $\begin{array}{l}88.6 \% \text { salt } \\
\text { rejection } \\
\text { after } 20 \mathrm{~h} \\
\text { operation }\end{array}$ & [12] \\
\hline VMD & $\begin{array}{l}\text { Commercial } \\
\text { PVDF }\end{array}$ & $\begin{array}{l}35,000 \\
\mathrm{mg} / \mathrm{L} \mathrm{NaCl}\end{array}$ & $\begin{array}{l}80 \mathrm{mg} / \mathrm{L} \\
\text { sodium } \\
\text { dodecyl } \\
\text { benzene } \\
\text { sulfonate }\end{array}$ & 11.7 & $\begin{array}{l}\text { Below } 2 \% \\
\text { after } 12 \mathrm{~h} \\
\text { operation }\end{array}$ & [34] \\
\hline VMD & $\begin{array}{l}\text { Commercial } \\
\text { PVDF }\end{array}$ & $\begin{array}{l}\text { Synthetic } \\
\text { CSG RO } \\
\text { brine }\end{array}$ & $\begin{array}{l}2,000 \text { ppm 2- } \\
\text { BE }\end{array}$ & 16 & $\begin{array}{l}99.97 \% \text { after } \\
72 \mathrm{~h} \\
\text { operation }\end{array}$ & This study \\
\hline
\end{tabular}

\subsection{Mechanism of penetration of VOCs}

Like some small organic particle, the "adsorption-desorption" mechanism was considered as the cause of the high mobility of the VOCs. In Fig. 11, 2-BE was selected to explain the mechanism for its noticeable characteristics affecting mass transfer of VOC in MD. Firstly, Fig. 11A shows that the 
hydrophobic head (usually an alkyl group of VOCs) of the 2-BE was attracted and attached on the surface of the hydrophobic membrane owing to their hydrophobic interactions (adsorption). Due to the highest log P of 2-BE among all the tested VOCs (Table 1), more 2-BE molecules tends to be attached on the membrane surface in this stage, greatly improving its mobility. Then hydrogen bonds between 2-BE and water molecules were formed. The intra-molecular hydrogen bonds between water and 2-BE were very strong because 3 bonds could be formed (2-BE had two acceptors and one donor) [26] (Fig. 11B). Fast mass transfer of 2-BE was achieved as it was "pushed" by the water molecules (Fig. 11C), the hydrophobic interaction was lost during the movement (desorption). The "adsorption-desorption" process can be repeated which promote the further travel of the VOCs through the membrane pores. Nevertheless, some 2-BE molecules would be trapped in the membrane pores due to its high molecule weight and boiling point.

At a smaller scale, Fig. 11D shows that partial pore wetting started to appear on the membrane surface pores due to the decrease of surface tension of feed solution, which was caused by the addition of relatively strong surfactant properties of 2-BE into the feed [12]. Also, by hydrogen bonding, some liquid water may be trapped inside of the membrane pores due to the engagement between the water molecule and large amounts of 2-BE previously remained in the pores. This mechanism applies to other VOCs that have surfactant property and ability to form hydrogen bonds with water. Acetic acid has slightly stronger surfactant strength and ability to form hydrogen bonds than IPA, and this explained its higher mass transfer rate during VMD in this study even though acetic acid had much lower vapour pressure than IPA. Also, the surfactant strength of acetic acid was much lower than 2-BE, so partial pore wetting did not occur during $24 \mathrm{~h}$ operation. Banat and Al-Shannag found similar phenomenon when studying on the recovery of dilute acetone-butanol-ethanol solvents from the aqueous solution through MD. Although butanol had the biggest molecular weight and lowest vapour pressure among the three solvents, the flux of butanol was significantly higher than acetone and ethanol at the same conditions [35]. The mechanism of the fast penetration of butanol can be explained as above because butanol has strong surfactant properties and can form hydrogen bonds with water molecules. 
Therefore, for mass transfer of the VOCs in MD system, strengths of surfactants properties and intramolecular hydrogen bonding with water molecules appear to be as important as the vapour pressure, which deserves further investigations.

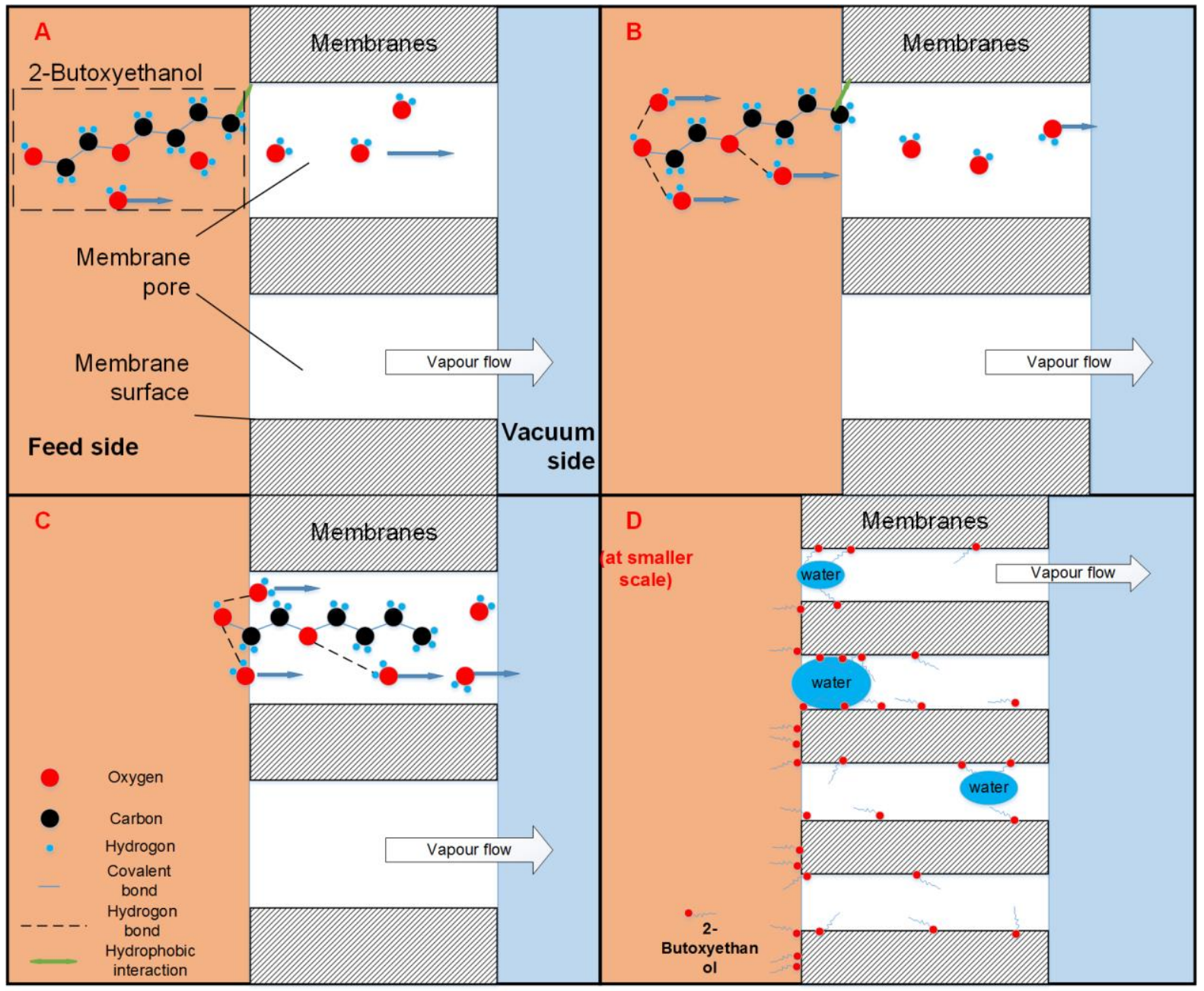

Fig. 11 Mechanism of the penetration of VOCs: A) 2-butoxyethanol (2-BE) molecules are attracted and adhere onto the membranes surface due to hydrophobic interactions between the alkyl head on the 2-BE and the hydrophobic surface of the membrane polymer; B) three hydrogen bonds are formed between the 2-BE and water molecules; C) the water vapours "push" the 2-BE molecules moving forward through the membrane pores; D) pore wetting starts to appear due to the surfactant properties of 2-BE

\section{Conclusions}


In this study, a series of experiments were conducted to systemically determine the impacts of various VOCs in the produced water on the VMD performance and membrane properties. Addition of 2-BE, acetic acid, and IPA into feed could increase the flux due to their mass transport. All the tested VOCs, except ethylene glycol, could easily penetrate the membranes as high concentrations of them were found in the permeate, without the occurrence of membrane wetting. High concentrations of the VOCs found in the permeate raised the concerns about pre- or post-treatment of VOCs for the MD system. It was unexpected that 2-BE had the highest mobility although it had the second lowest vapour pressure among the tested VOCs; the concentration of 2-BE was much higher in the permeate than in the feed after 24 $\mathrm{h}$ operation. Moreover, due to the strong surfactant property of 2-BE, liquid water was found in the pores of the membrane that had treated the feed containing 2-BE. Also, contact angle of the HF membranes was greatly decreased due to the existence of VOCs on the membranes surfaces and wetted pores. A longer operation time would see a further movement of the liquid water through the membranes, a progress from partial pore wetting to complete pore wetting, and the salt rejection hence dropped. Therefore, this study concluded that the VOCs existing in the produced water could have strong impacts on the quality of the final permeate and MD performance. It was also found that the strengths of surfactant and intra-molecular hydrogen bonds between the water and the VOCs play an important role as the vapour pressure of the VOCs in MD operation in terms of their mass transfer. It explains that ethylene glycol, a VOC with no surfactant property, had no impact on MD performance and permeate quality, while 2-BE, a VOC with strong surfactant properties and capable of forming intra-molecular hydrogen bonds with water, had superior impacts on MD flux and permeate quality, although 2-BE and ethylene glycol share close boiling point. A further study regarding the removal of the VOCs by applying a pre-treatment process has been proposed to improve the long-term MD permeation performance, especially in terms of the permeate quality.

\section{Acknowledgement}

This research was supported by a Grant (17IFIP-B065893-05) from the Industrial Facilities \& Infrastructure Research Program funded by Ministry of Land, Infrastructure and Transport of Korean 
Government. The authors also acknowledge the support by an Australian Government Research Training Program Scholarship and the Grant from the ARC Future Fellowship (FT140101208).

\section{Reference}

[1] I. Hamawand, T. Yusaf, S.G. Hamawand, Coal seam gas and associated water: A review paper, Renewable and Sustainable Energy Reviews, 22 (2013) 550-560.

[2] B.C. Gordalla, U. Ewers, F.H. Frimmel, Hydraulic fracturing: a toxicological threat for groundwater and drinking-water?, Environmental earth sciences, 70 (2013) 3875-3893.

[3] K.G. Dahm, K.L. Guerra, P. Xu, J.E. Drewes, Composite geochemical database for coalbed methane produced water quality in the Rocky Mountain region, Environmental science \& technology, 45 (2011) 7655-7663.

[4] L.D. Nghiem, T. Ren, N. Aziz, I. Porter, G. Regmi, Treatment of coal seam gas produced water for beneficial use in Australia: a review of best practices, Desalination and Water Treatment, 32 (2011) 316-323.

[5] A. Averina, M. Rasul, S. Begum, Management of coal seam gas (CSG) by-product water: a case study on spring gully mine site in Queensland, Australia, in: 2nd International Conference on Waste Management, Water Pollution, Air Pollution, Indoor Climate (WWAI'08), Corfu, Greece, 2008, pp. 2628.

[6] H.C. Duong, A.R. Chivas, B. Nelemans, M. Duke, S. Gray, T.Y. Cath, L.D. Nghiem, Treatment of RO brine from CSG produced water by spiral-wound air gap membrane distillation - A pilot study, Desalination, 366 (2015) 121-129.

[7] Y.C. Woo, Y. Kim, W.-G. Shim, L.D. Tijing, M. Yao, L.D. Nghiem, J.-S. Choi, S.-H. Kim, H.K. Shon, Graphene/PVDF flat-sheet membrane for the treatment of RO brine from coal seam gas produced water by air gap membrane distillation, Journal of Membrane Science, 513 (2016) 74-84.

[8] Y.C. Woo, Y. Chen, L.D. Tijing, S. Phuntsho, T. He, J.-S. Choi, S.-H. Kim, H.K. Shon, CF4 plasmamodified omniphobic electrospun nanofiber membrane for produced water brine treatment by membrane distillation, Journal of Membrane Science, 529 (2017) 234-242.

[9] A. Alkhudhiri, N. Darwish, N. Hilal, Produced water treatment: application of air gap membrane distillation, Desalination, 309 (2013) 46-51.

[10] S. Tavakkoli, O.R. Lokare, R.D. Vidic, V. Khanna, A techno-economic assessment of membrane distillation for treatment of Marcellus shale produced water, Desalination, 416 (2017) 24-34.

[11] D.L. Shaffer, L.H. Arias Chavez, M. Ben-Sasson, S. Romero-Vargas Castrillón, N.Y. Yip, M. Elimelech, Desalination and reuse of high-salinity shale gas produced water: drivers, technologies, and future directions, Environmental science \& technology, 47 (2013) 9569-9583. 
[12] N.G.P. Chew, S. Zhao, C.H. Loh, N. Permogorov, R. Wang, Surfactant effects on water recovery from produced water via direct-contact membrane distillation, Journal of Membrane Science, 528 (2017) 126-134.

[13] M. Yao, Y.C. Woo, L. Tijing, C. Cesarini, H.K. Shon, Improving Nanofiber Membrane Characteristics and Membrane Distillation Performance of Heat-Pressed Membranes via Annealing Post-Treatment, Applied Sciences, 7 (2017) 78.

[14] L. Eykens, K. De Sitter, C. Dotremont, L. Pinoy, B. Van der Bruggen, Wetting resistance of commercial membranes in waste streams containing surfactants and oil in membrane distillation, Applied Sciences, 7 (2017) 118-130.

[15] W. Orem, C. Tatu, M. Varonka, H. Lerch, A. Bates, M. Engle, L. Crosby, J. McIntosh, Organic substances in produced and formation water from unconventional natural gas extraction in coal and shale, International Journal of Coal Geology, 126 (2014) 20-31.

[16] S.L. Brantley, D. Yoxtheimer, S. Arjmand, P. Grieve, R. Vidic, J. Pollak, G.T. Llewellyn, J. Abad, C. Simon, Water resource impacts during unconventional shale gas development: The Pennsylvania experience, International Journal of Coal Geology, 126 (2014) 140-156.

[17] Y. Lester, I. Ferrer, E.M. Thurman, K.A. Sitterley, J.A. Korak, G. Aiken, K.G. Linden, Characterization of hydraulic fracturing flowback water in Colorado: Implications for water treatment, Science of the Total Environment, 512 (2015) 637-644.

[18] A. Alkhudhiri, N. Darwish, N. Hilal, Membrane distillation: a comprehensive review, Desalination, 287 (2012) 2-18.

[19] Z. Jin, S.H. Zhang, X.G. Jian, Hydrophobic modification of poly (phthalazinone ether sulfone ketone) hollow fiber membrane for vacuum membrane distillation, Journal of Membrane Science, 310 (2008) 20-27.

[20] M. Yao, Y.C. Woo, L.D. Tijing, W.-G. Shim, J.-S. Choi, S.-H. Kim, H.K. Shon, Effect of heatpress conditions on electrospun membranes for desalination by direct contact membrane distillation, Desalination, 378 (2016) 80-91.

[21] Y.C. Woo, L.D. Tijing, W.-G. Shim, J.-S. Choi, S.-H. Kim, T. He, E. Drioli, H.K. Shon, Water desalination using graphene-enhanced electrospun nanofiber membrane via air gap membrane distillation, Journal of Membrane Science, 520 (2016) 99-110.

[22] M. Garcia-Payo, M.A. Izquierdo-Gil, C. Fernández-Pineda, Air gap membrane distillation of aqueous alcohol solutions, Journal of Membrane Science, 169 (2000) 61-80.

[23] A. Rodríguez, L. Serrano, A. Moral, A. Pérez, L. Jiménez, Use of high-boiling point organic solvents for pulping oil palm empty fruit bunches, Bioresource Technology, 99 (2008) 1743-1749.

[24] S. Meng, Y. Ye, J. Mansouri, V. Chen, Fouling and crystallisation behaviour of superhydrophobic nano-composite PVDF membranes in direct contact membrane distillation, Journal of Membrane Science, 463 (2014) 102-112. 
[25] G. Naidu, S. Jeong, S. Vigneswaran, Interaction of humic substances on fouling in membrane distillation for seawater desalination, Chemical Engineering Journal, 262 (2015) 946-957.

[26] R.L. Brinkley, R.B. Gupta, Intra-and intermolecular hydrogen bonding of 2-methoxyethanol and 2-butoxyethanol in n-hexane, Industrial \& engineering chemistry research, 37 (1998) 4823-4827.

[27] D. Murphy, M.N. de Pinho, An ATR-FTIR study of water in cellulose acetate membranes prepared by phase inversion, Journal of Membrane Science, 106 (1995) 245-257.

[28] U. Kaatze, R. Pottel, A. Schumacher, Dielectric spectroscopy of 2-butoxyethanol/water mixtures in the complete composition range, Journal of Physical Chemistry, 96 (1992).

[29] G. Vazquez, E. Alvarez, J.M. Navaza, Surface tension of alcohol water+ water from 20 to 50. degree. C, Journal of chemical and engineering data, 40 (1995) 611-614.

[30] M. D'Angelo, G. Onori, A. Santucci, Study of aggregation of n-butoxyethanol in water by compressibility and surface tension measurements, Chemical physics letters, 220 (1994) 59-63.

[31] M. Rezaei, D.M. Warsinger, J.H. Lienhard V, W.M. Samhaber, Wetting prevention in membrane distillation through superhydrophobicity and recharging an air layer on the membrane surface, Journal of Membrane Science, 530 (2017) 42-52.

[32] F.E. Ahmed, B.S. Lalia, R. Hashaikeh, Membrane-based detection of wetting phenomenon in direct contact membrane distillation, Journal of Membrane Science, 535 (2017) 89-93.

[33] P.-J. Lin, M.-C. Yang, Y.-L. Li, J.-H. Chen, Prevention of surfactant wetting with agarose hydrogel layer for direct contact membrane distillation used in dyeing wastewater treatment, Journal of Membrane Science, 475 (2015) 511-520.

[34] D. Tong, X. Wang, M. Ali, C.Q. Lan, Y. Wang, E. Drioli, Z. Wang, Z. Cui, Preparation of Hyflon AD60/PVDF composite hollow fiber membranes for vacuum membrane distillation, Separation and Purification Technology, 157 (2016) 1-8.

[35] F. Banat, M. Al-Shannag, Recovery of dilute acetone-butanol-ethanol (ABE) solvents from aqueous solutions via membrane distillation, Bioprocess Engineering, 23 (2000) 643-649. 